\title{
Effect of silica fume and MIRHA on thermal conductivity of cement paste
}

\author{
S. A. Farhan, M. F. Khamidi, M. H. Murni, M. F. Nuruddin, \\ A. Idrus \& A. M. Al Yacouby \\ Civil Engineering Department, \\ Universiti Teknologi PETRONAS, Malaysia
}

\begin{abstract}
Increased usage of air-conditioners in buildings leads to higher levels of electricity and energy consumption. Thermal insulation improves energyefficiency of buildings by retarding heat flow through building envelopes and thus reducing indoor cooling load. This research investigates the potential of two cement replacement materials, which are silica fume and Microwave Incinerated Rice Husk Ash (MIRHA), incorporated in cement paste as thermal insulation. Samples of cement paste with varying volumes of silica fume and MIRHA were prepared and evaluated on their thermal conductivity values. Their viability as building materials were then evaluated by measuring their permeable porosities and compressive strengths at three (3), seven (7) and 28 days of curing. Results show that higher dosage of silica fume and MIRHA in cement paste lead to lower thermal conductivity but negatively affect compressive strength and permeable porosity. MIRHA reduces thermal conductivity more efficiently than silica fume but leads to a faster decline in compressive strength and increase in permeable porosity. The lowest thermal conductivity value obtained in this experiment was $0.4273 \mathrm{Wm}^{-1} \mathrm{~K}^{-1}$, which was achieved by samples with MIRHA incorporated at $25 \%$ of cement paste volume.

Keywords: silica fume, microwave incinerated rice husk ash, MIRHA, cement paste, cement replacement material, thermal conductivity, thermal insulation, concrete, compressive strength, permeable porosity.
\end{abstract}




\section{Introduction}

Buildings are designed to shelter occupants and provide living space that is thermally comfortable for its occupants. In developing hot-humid countries such as Malaysia, many urban housing and office buildings are equipped with airconditioning systems that can lower indoor temperature and humidity and provide occupants with their desired thermal comfort. However, increased usage of air-conditioners in buildings leads to higher levels of electricity and energy consumption. A study by Centre of Environment, Technology and Development (CETDEM) [1] in Malaysia found that $45 \%$ of the average household electricity consumption is due to the usage of air conditioners. With the threat of global warming and drastic increase in energy cost, keeping indoor living spaces cool is becoming an increasingly important theme for researchers and industry practitioners in this area.

Al-Homoud [2] reported that thermal insulation improves energy-efficiency of buildings by retarding heat flow through building envelopes and thus reducing indoor cooling load. Cement paste is a fundamental constituent of building envelopes and improving its thermal insulation capability can significantly contribute towards reducing the usage of air-conditioners and mitigating the effects of global warming.

Silica fume and Microwave Incinerated Rice Husk Ash (MIRHA) can lower thermal conductivity of cement paste by partially replacing cement content. American Concrete Institute (ACI) [3] reported that silica fume is a by-product of the reduction of high purity quartz with coal in electric furnaces in the production of silicon and ferrosilicon alloys. MIRHA is produced from the burning process of paddy husk which creates pozzolanic materials that contains substantial amount of silica. Recent research work by Sensale [4] has shown that partial replacement of Ordinary Portland Cement (OPC) with rice husk ash improves concrete performance.

This research evaluates the effect of partially replacing OPC in cement with silica fume and MIRHA on thermal conductivity. Cement paste cube samples with varying volumes of silica fume and MIRHA were prepared. Thermal conductivity tests were performed on samples to investigate the effect of silica fume and MIRHA on the thermal conductivity of cement paste. Permeable porosity and compressive strength tests were conducted to evaluate the viability of each cement paste mix as constituent materials in buildings.

\section{Methodology}

\subsection{Preparation of constituent materials}

Ordinary Portland Cement (OPC), free water and silica fume used were selected and prepared based on standards outlined in BS EN 197-1-2000, BS 3148:1980 and BS EN 13262 Part 1:2005 respectively.

For the preparation of MIRHA, dried rice husks were burnt in an automatic microwave incinerator at temperatures of up to $400^{\circ} \mathrm{C}$ in a one-phase burning 
process. The incinerator used in this research adopted the Air Cooled Magnetron System with a chamber capacity of $1 \mathrm{~m}^{3}$. After burning, MIRHA was ground in a ball mill with the Los Angeles Abrasion Machine for 3000 times to achieve the desired fineness.

\subsection{Preparation of cement paste samples}

Cement paste with 0.5 water-cement ratio was mixed according to procedures outlined in ASTM C305-99. Eleven (11) types of mixes were prepared as outlined in Table 1. After mixing, cement paste cube samples with dimensions of $50 \mathrm{~mm} \times 50 \mathrm{~mm} \times 50 \mathrm{~mm}$ and $150 \mathrm{~mm} \times 150 \mathrm{~mm} \times 150 \mathrm{~mm}$ were prepared by casting cement paste in steel moulds for 24 hours. After casting, samples were cured with water in the curing tank at $25 \pm 2{ }^{\circ} \mathrm{C}$ water temperatures to aid hydration and avoid shrinkage cracking. The curing process was conducted in accordance with BS EN 12390-2:2000. Dry density values were measured at 28 days of curing time.

Table 1: $\quad$ Description of sample mixes.

\begin{tabular}{|c|c|}
\hline $\begin{array}{c}\text { Sample Mix Type } \\
\text { Number }\end{array}$ & Sample Mix Description \\
\hline 1 & No cement replacement material \\
\hline 2 & $5 \%$ silica fume as cement replacement material \\
\hline 3 & $10 \%$ silica fume as cement replacement \\
material
\end{tabular}

\subsection{Evaluation of compressive strength}

Compressive strength tests were performed on $50 \mathrm{~mm}$ x $50 \mathrm{~mm}$ x $50 \mathrm{~mm}$ cement paste cube samples at three (3), seven (7) and 28 days of curing time in accordance with BS EN 12390-3:2002 using the Digital Compressive Testing Machine. Samples were subjected to compressive loads at a rate of $0.9 \mathrm{kNs}^{-1}$. Compressive strength values were taken as the maximum load that each sample can sustain before failure per unit of cross-sectional area. An average reading of three (3) samples was taken for each type of sample mix. 


\subsection{Evaluation of permeable porosity}

Permeable porosity tests were performed on $50 \mathrm{~mm}$ x $50 \mathrm{~mm}$ x $50 \mathrm{~mm}$ cement paste cube samples at 28 days of curing time using the vacuum saturation method in accordance with ASTM C1202-1997. At 28 days of curing time, samples were dried in an oven at $110 \pm 10^{\circ} \mathrm{C}$ and weighed at 24-hour intervals until the loss in weight did not exceed 1\% per interval as mentioned in ASTM C332. Vacuum saturation tests were then performed to obtain saturated surfacedry mass of samples in air $\left(\mathrm{W}_{\mathrm{s}}\right)$, oven-dry mass of samples in air $\left(\mathrm{W}_{\mathrm{d}}\right)$ and buoyant mass of saturated samples in water $\left(\mathrm{W}_{\mathrm{b}}\right)$ for calculation of permeable porosity as shown in eqn. (1).

$$
\text { Permeable porosity }=\frac{\mathrm{W}_{\mathrm{s}}-\mathrm{W}_{\mathrm{d}}}{\mathrm{W}_{\mathrm{s}}-\mathrm{W}_{\mathrm{b}}} \times 100 \%
$$

An average reading of three (3) samples was taken for each type of sample mix.

\subsection{Evaluation of thermal conductivity}

Thermal conductivity tests were performed on $150 \mathrm{~mm}$ x $150 \mathrm{~mm} \times 150 \mathrm{~mm}$ cement paste cube samples to measure thermal conductivity for each type of sample mix. At 28 days of curing time, samples were dried in an oven at $110 \pm$ $10^{\circ} \mathrm{C}$ and weighed at 24-hour intervals until the loss in weight did not exceed $1 \%$ per interval as mentioned in ASTM C332. Thermal conductivity were then measured using the Kemtherm Quick Thermal Conductivity Meter (QTM-D3) which functions based on the hot wire method as explained in ASTM C1113-90. An average reading of three (3) samples was taken for each type of sample mix.

\section{Results and discussions}

Table 2 outlines abbreviations used in this subtopic for each sample mix to simplify presentation of tables and graphs.

Table 2: $\quad$ Abbreviations of sample types.

\begin{tabular}{|c|c|}
\hline Abbreviation & Sample Description \\
\hline Control & No cement replacement material \\
\hline SF5 & $5 \%$ silica fume as cement replacement material \\
\hline SF10 & $10 \%$ silica fume as cement replacement material \\
\hline SF15 & $15 \%$ silica fume as cement replacement material \\
\hline SF20 & $20 \%$ silica fume as cement replacement material \\
\hline SF25 & $25 \%$ silica fume as cement replacement material \\
\hline M5 & $5 \%$ MIRHA as cement replacement material \\
\hline M10 & $10 \%$ MIRHA as cement replacement material \\
\hline M15 & $15 \%$ MIRHA as cement replacement material \\
\hline M20 & $20 \%$ MIRHA as cement replacement material \\
\hline M25 & $25 \%$ MIRHA as cement replacement material \\
\hline
\end{tabular}




\subsection{Effect of silica fume and MIRHA on dry density}

Fig. 1 shows that incorporation of silica fume or MIRHA in cement paste decreases its dry density. For the same dosage, samples with MIRHA have lower dry density compared to samples with silica fume because the specific gravity of MIRHA is lower than silica fume. The control sample has the highest density because the specific gravity of OPC is higher than silica fume and MIRHA.

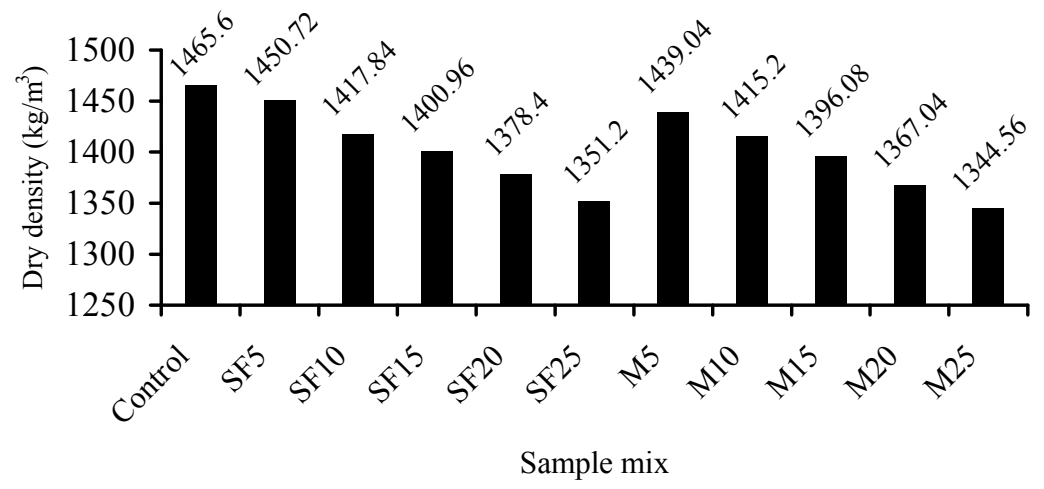

Figure 1: $\quad$ Dry density values for all samples.

\subsection{Effect of silica sume and MIRHA on compressive strength}

Fig. 2 to 4 show compressive strength values obtained at three (3), seven (7) and 28 days of curing time respectively.

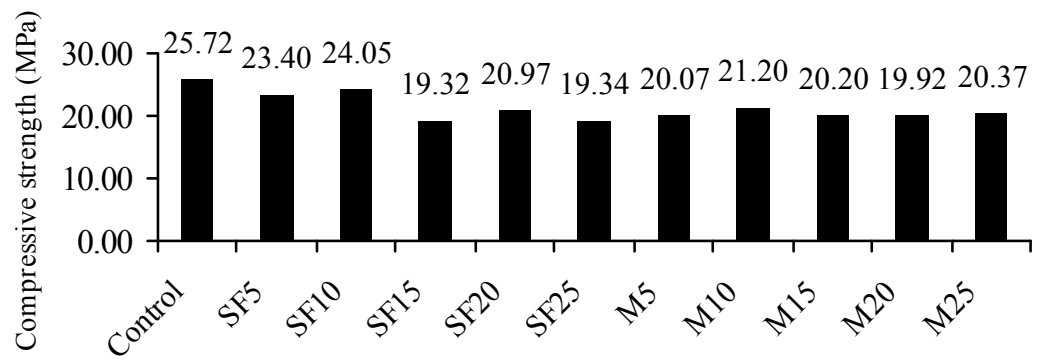

Sample mix

Figure 2: $\quad$ Compressive strength values at three (3) days of curing time for all samples. 


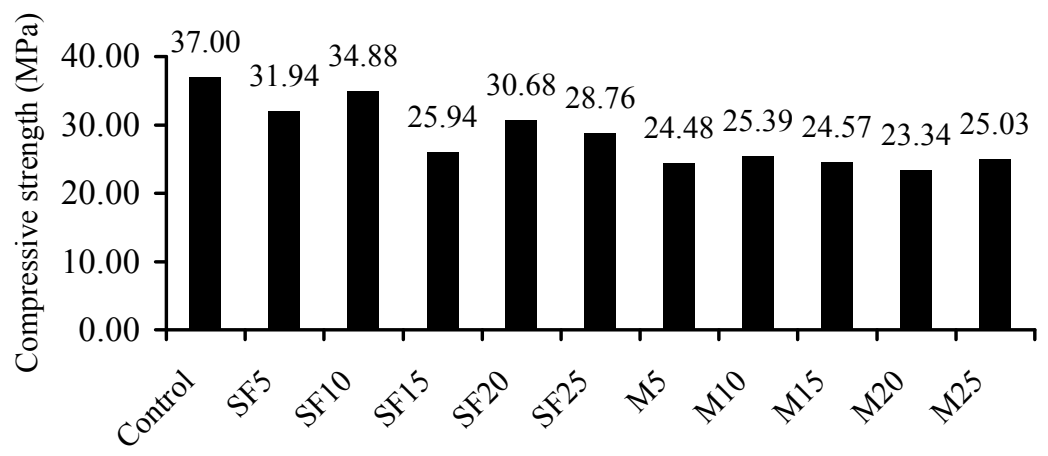

Sample mix

Figure 3: Compressive strength values at seven (7) days of curing time for all samples.

Fig. 4 shows that incorporation of silica fume and MIRHA in cement paste decreases its compressive strength. Reduction in compressive strength due to MIRHA is larger than that of silica fume.

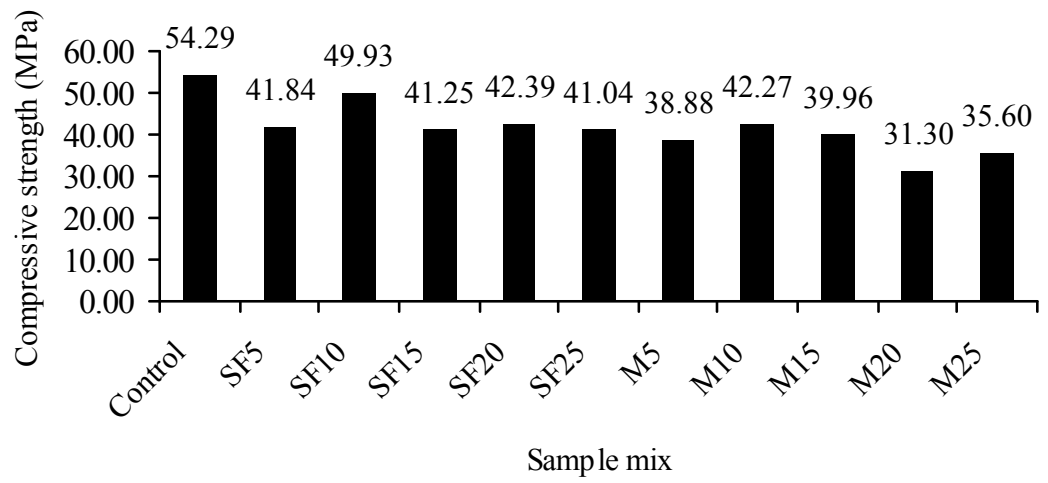

Figure 4: Compressive strength values at 28 days of curing time for all samples.

Fig. 5 and 6 conclude that there is no clear correlation between the dosage of silica fume and MIRHA and compressive strength. For samples with silica fume, the highest compressive strength measured was $49.93 \mathrm{MPa}$, which was obtained by sample SF10. For samples with MIRHA, the highest compressive strength measured was $42.27 \mathrm{MPa}$, which was obtained by sample M10. 


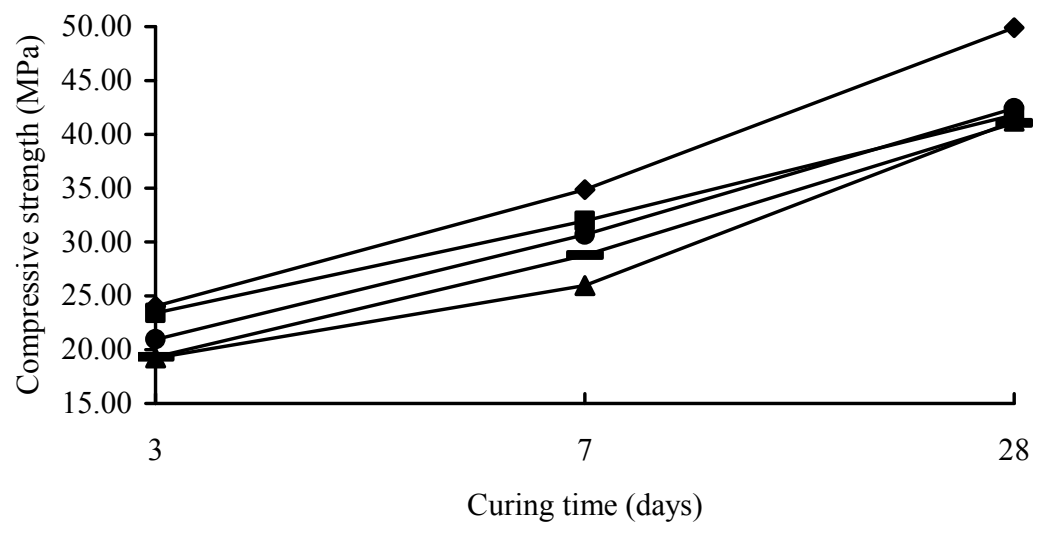

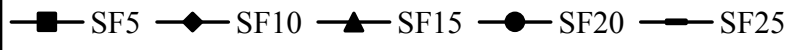

Figure 5: Compressive strength values of cement paste samples with silica fume incorporated as cement replacement material.

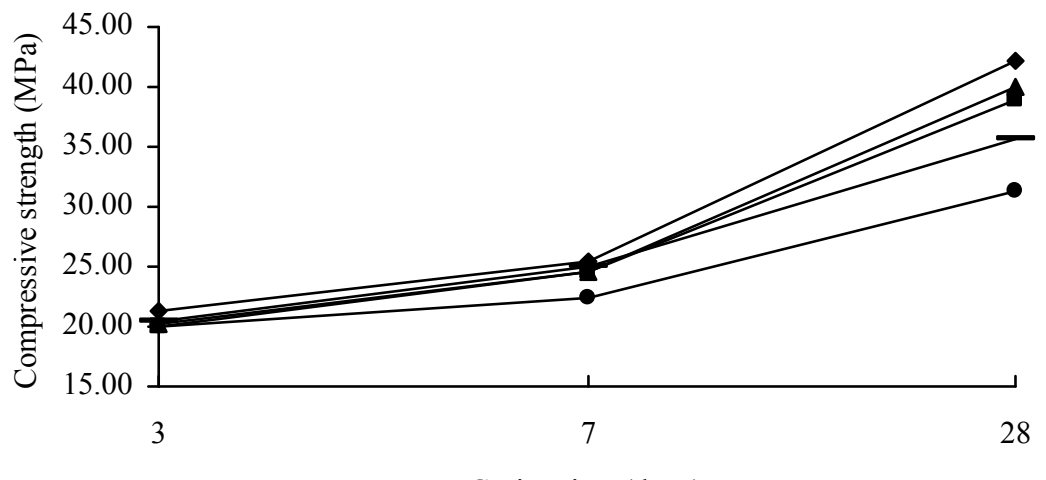

Curing time (days)

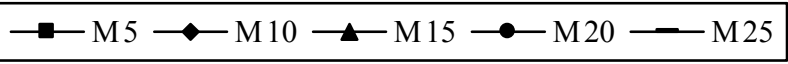

Figure 6: Compressive strength values of cement paste samples with MIRHA incorporated as cement replacement material.

\subsection{Effect of silica fume and MIRHA on permeable porosity}

Fig. 7 shows that incorporation of silica fume and MIRHA in cement paste increases its porosity. Higher dosages of silica fume and MIRHA lead to higher porosity values. Increase in porosity due to MIRHA is higher than that of silica 
fume. For samples with silica fume, the highest permeable porosity measured was $31.71 \%$, which was obtained by sample SF25. For samples with MIRHA, the highest permeable porosity measured was $32.19 \%$, which was obtained by sample M25.

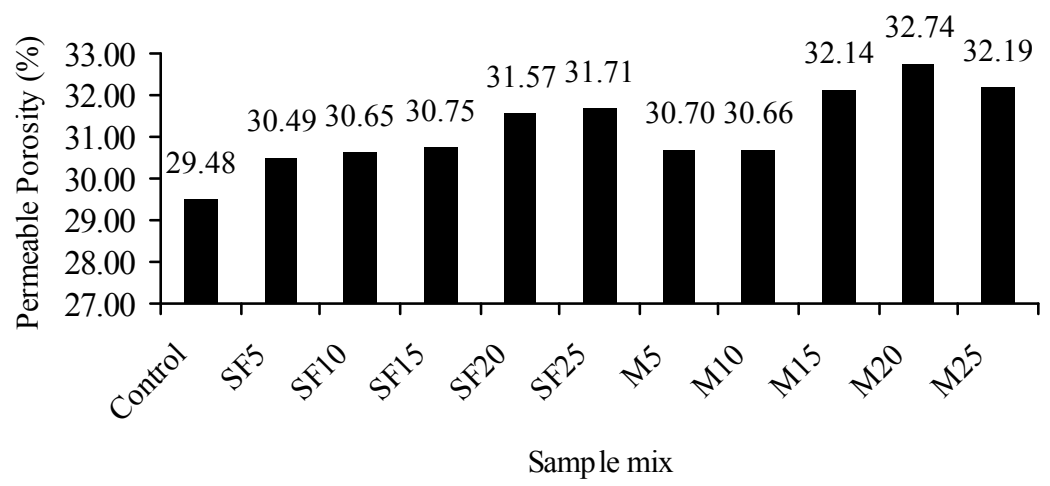

Figure 7: $\quad$ Permeable porosity values for all samples.

\subsection{Effect of silica fume and MIRHA on thermal conductivity}

Fig. 8 shows that silica fume and MIRHA decreases thermal conductivity and thus improves thermal insulation. Higher dosage of silica fume and MIRHA lead to lower thermal conductivity. Decrease in thermal conductivity due to MIRHA is higher than that of silica fume. Figs. 1 and 8 show that thermal conductivity is a function of density. Higher dosage of silica fume and MIRHA contributes to lower dry density and thermal conductivity.

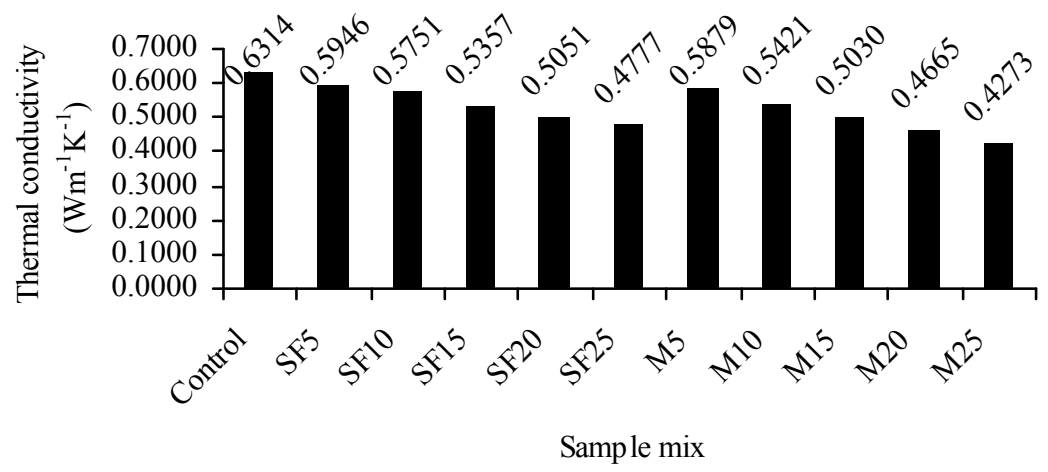

Figure 8: Thermal conductivity values for all samples. 
Demirboga and Gul [5] conducted a study on the effect of silica fume and fly ash on thermal conductivity of lightweight concrete and reported that thermal conductivity decreased due to the decrease in density caused by the replacement of OPC with silica fume and fly ash which possess lower specific gravities than OPC. Fu and Chung [6] reported that latex, methylcellulose and silica fume decreased the density and thermal conductivity of cement paste. Demirboga [7] reported that thermal conductivity decreased due to decreasing density of concrete which results in an increase in void content.

\section{Conclusion}

Higher dosage of cement replacement material reduces dry density of cement paste, which leads to lower thermal conductivity. MIRHA reduces thermal conductivity at a higher rate compared to silica fume.

Despite the positive effect on thermal conductivity, incorporation of silica fume and MIRHA in cement paste leads to increased permeable porosity and lower compressive strength. Results show that higher dosage of silica fume and MIRHA in cement paste lead to lower thermal conductivity but negatively affect compressive strength and permeable porosity. MIRHA reduces thermal conductivity more efficiently than silica fume but leads to a higher rate of decline in compressive strength and increase in permeable porosity. The lowest thermal conductivity measured was $0.4273 \mathrm{Wm}^{-1} \mathrm{~K}^{-1}$ which was achieved by M25 and presents a $32.3 \%$ reduction in thermal conductivity relative to the control sample.

\section{References}

[1] Aun, C. S., Applying MS1525:2007: Code of Practice on Energy Efficiency and Use of Renewable Energy. CPD Seminar, Pertubuhan Arkitek Malaysia (PAM): Malaysia, 2009.

[2] Al-Homoud, M. S., Performance characteristics and practical applications of common building thermal insulation materials. Journal of Building and Environment, 40, pp. 353-366, 2005.

[3] ACI Committee, Silica fume in concrete: preliminary report. ACI Materials Journal, March-April, pp. 158-166, 2006.

[4] Sensale, G. R., Strength development of concrete with rice husk ash. Cement and Concrete Composites, 28, pp. 158-160, 2006.

[5] Demirboga, R. and Gul, R., The effects of expanded perlite aggregate, silica fume and fly ash on the thermal conductivity of lightweight concrete. Journal of Cement and Concrete Research, 33(5), pp. 723-727, 2003.

[6] Fu, X. and Chung, D. D., Effects of silica fume, latex, methycellulose and carbon fibers on the thermal conductivity and specific heat of cement paste. Journal of Cement and Concrete Research, 27, 1799-1804, 1997.

[7] Demirboga, R., Thermo-mechanical properties of sand and high volume mineral admixtures. Journal of Energy and Buildings, 35(5), 435-439, 2003. 